\title{
Lubs X-Linked Mental Retardation Syndrome
}

National Cancer Institute

\section{Source}

National Cancer Institute. Lubs X-Linked Mental Retardation Syndrome. NCI Thesaurus.

Code C126747.

An X-linked inherited syndrome caused by duplication or triplication of the gene encoding methyl-CpG-binding protein-2 (MECP2). It is characterized by mental retardation, infantile hypotonia, mild dysmorphic features, poor speech development, autistic features, seizures, progressive spasticity, and recurrent infections. 